\title{
Type 2 (non-insulin-dependent) diabetes mellitus and cardiovascular disease - putative association via common antecedents; further evidence from the Whitehall Study
}

\author{
R.J.Jarrett ${ }^{1}$ and M.J.Shipley ${ }^{2}$ \\ ${ }^{1}$ Division of Community Health, United Medical and Dental Schools of Guy's and St. Thomas's Hospitals (Guy's Campus), and \\ ${ }^{2}$ Division of Medical Statistics and Epidemiology, London School of Hygiene and Tropical Medicine, U.K.
}

\begin{abstract}
Summary. Fifteen year mortality rates are reported for men participating in the Whitehall Study in 1968-70. Subjects were divided into four groups - normoglycaemic (centiles 1-95 of the blood glucose distribution: $n=17,051$ ), glucose intolerant (centiles 96-100: $n=999$ ), newly diagnosed diabetic patients $(n=56)$ and previously diagnosed diabetic patients $(n=121)$ treated with diet \pm tablets. Relative risks for all causes mortality and from coronary and cardiovascular disease deaths were calculated. Age adjusted relative risks were highest in the newly diagnosed diabetic patients and were also increased in glucose intolerant and previously diagnosed diabetic men $(p<0.05)$, but did not increase with in-
\end{abstract}

creasing duration of diabetes. With adjustment for other risk factors, relative risks were similar in newly diagnosed and previously diagnosed diabetic men. There was no significant linear trend of adjusted relative risks with duration of diabetes when all diabetic men were pooled and person years at risk calculated. The lack of effect of duration upon relative risk together with other observations suggests common, possibly genetic, antecedents of both Type 2 (non-insulin-dependent) diabetes and coronary heart disease.

Key words: Type 2 (non-insulin-dependent) diabetes mellitus, diabetes duration, cardiovascular disease mortality.
It is commonly believed that the increased risk of cardiovascular disease (CVD) associated with Type 2 (non-insulin-dependent) diabetes mellitus is due to the metabolic abnormalities of the latter condition. This view has been challenged $[1,2]$ and an alternative hypothesis proposed that CVD and Type 2 diabetes mellitus are associated disorders, possibly linked genetically [1]. There are several lines of evidence, but a principal one lies in the absence of an association between duration of diabetes and the risk of CVD in contrast to the demonstrable and consistently strong association between duration of diabetes and microvascular disease; in particular diabetic retinopathy [3]. However, there are few prospective studies with relevant data, one of the exceptions being the Whitehall Study, in which 10-year mortality rates from all causes, CVD and coronary heart disease (CHD) were not related to duration of disease in 121 subjects with previously diagnosed Type 2 diabetes mellitus who participated in the survey [4]. The present paper presents data on mortality at 15 years of follow up and also compares mortality rates in the previously known diabetic subjects with those in the newly diagnosed diabetic men, in men in the upper 5 percentiles of the distribution of $2 \mathrm{~h}$ post-load blood glucose levels $(5.4-11.0 \mathrm{mmol} / \mathrm{l})$, referred to as 'glucose-intolerant', who also have an in- creased risk of cardiovascular disease [5], and in men who were normoglycaemic.

\section{Subjects and methods}

In the Whitehall Study, cardio-respiratory screening of male civil servants working in London was carried out between 1967 and 1969. The methods of the study have been previously reported [6]. Men known to be diabetic could participate in the screening survey, but were not required to take the oral glucose load. Information on duration of diabetes and the kind of treatment was sought on the questionnaire completed by each participant. Non-diabetic men drank $50 \mathrm{~g}$ glucose in the morning after an overnight fast and capillary blood was taken $2 \mathrm{~h}$ later for blood glucose measurement. Those with levels above $11.0 \mathrm{mmol} / 1$, subsequently approved by the W.H.O. Study Group on Diabetes Mellitus [7] as a suitable epidemiological definition of diabetes, were referred to their general practitioner as probably diabetic, and are designated as newly diagnosed diabetic patients. Additional measurements included height, weight, blood pressure and capillary plasma cholesterol. Smoking habits and employment grade were derived from the questionnaire. Electrocardiographs were recorded and coded according to the Minnesota Code [8].

Positive ECG signs (Whitehall criteria) were taken as one or more of the following Minnesota Code items: Q/QS waves (codes 1.1-1.3); S-T depressions (codes 4.1-4.4); T-wave inversion or flattening (codes 5.1-5.3); left bundle-branch block (7.1).

The records of the men held at the National Health Service Central Register were identified and flagged. Thus, notification of a 
Table 1. Age adjusted mortality rates (per 1000 person years), number of deaths and relative risks with $95 \%$ confidence intervals

\begin{tabular}{|c|c|c|c|c|c|c|c|c|c|c|}
\hline \multirow{2}{*}{$\begin{array}{l}\text { Glycaemia } \\
\text { group }\end{array}$} & \multirow{2}{*}{$\begin{array}{l}\text { Popu- } \\
\text { lation }\end{array}$} & \multicolumn{3}{|c|}{ All causes } & \multicolumn{3}{|c|}{ Coronary heart disease } & \multicolumn{3}{|c|}{ All cardiovascular disease } \\
\hline & & Rate & $\begin{array}{l}\text { No. } \\
\text { deaths }\end{array}$ & $\begin{array}{l}\text { RR } \\
(95 \% \mathrm{CI})\end{array}$ & Rate & $\begin{array}{l}\text { No. } \\
\text { deaths }\end{array}$ & $\begin{array}{l}\text { RR } \\
(95 \% \mathrm{CI})\end{array}$ & Rate & $\begin{array}{l}\text { No. } \\
\text { deaths }\end{array}$ & $\begin{array}{l}\text { RR } \\
(95 \% \mathrm{CI})\end{array}$ \\
\hline Normoglycaemic & 17,051 & 12.2 & 2774 & 1.0 & 4.7 & 1084 & 1.0 & 6.4 & 1458 & 1.0 \\
\hline $\begin{array}{l}\text { Glucose } \\
\text { intolerant }\end{array}$ & 999 & 15.9 & 239 & $\begin{array}{l}1.3 \\
(1.1 ; 1.5)\end{array}$ & 6.7 & 101 & $\begin{array}{l}1.4 \\
(1.2 ; 1.8)\end{array}$ & 8.8 & 134 & $\begin{array}{l}1.4 \\
(1.2 ; 1.7)\end{array}$ \\
\hline $\begin{array}{l}\text { Newly diagnosed } \\
\text { diabetic patient }\end{array}$ & 56 & 39.8 & 30 & $\begin{array}{l}2.6 \\
(1.8 ; 3.7)\end{array}$ & 28.1 & 17 & $\begin{array}{l}3.9 \\
(2.4 ; 6.4)\end{array}$ & 31.5 & 20 & $\begin{array}{l}3.7 \\
(2.1 ; 5.2)\end{array}$ \\
\hline \multicolumn{11}{|l|}{$\begin{array}{l}\text { Known duration } \\
\text { of diabetes at } \\
\text { examination: }\end{array}$} \\
\hline$\leqslant 2$ years & 35 & 23.7 & 12 & $\begin{array}{l}1.7 \\
(1.0 ; 3.0)\end{array}$ & 9.9 & 5 & $\begin{array}{l}1.9 \\
(0.8 ; 4.5)\end{array}$ & 13.2 & 7 & $\begin{array}{l}1.9 \\
(0.9 ; 4.0)\end{array}$ \\
\hline $3-6$ years & 43 & 31.6 & 20 & $\begin{array}{l}2.2 \\
(1.4 ; 3.5)\end{array}$ & 13.9 & 8 & $\begin{array}{l}2.4 \\
(1.2 ; 4.8)\end{array}$ & 17.7 & 12 & $\begin{array}{l}2.6 \\
(1.5 ; 4.5)\end{array}$ \\
\hline$\geqslant 7$ years & 43 & 25.7 & 15 & $\begin{array}{l}1.8 \\
(1.1 ; 3.0)\end{array}$ & 12.2 & 8 & $\begin{array}{l}2.6 \\
(1.3 ; 5.1)\end{array}$ & 12.2 & 8 & $\begin{array}{l}1.9 \\
(0.9 ; 3.7)\end{array}$ \\
\hline
\end{tabular}

$\mathrm{RR}=$ relative risk $; 95 \% \mathrm{CI}=95 \%$ confidence interval

Table 2. Relative risks with $95 \%$ confidence intervals controlling for major risk factors

\begin{tabular}{|c|c|c|c|c|c|c|}
\hline \multirow[t]{2}{*}{ Glycaemia group } & \multicolumn{2}{|l|}{ All causes } & \multicolumn{2}{|c|}{ Coronary heart disease } & \multicolumn{2}{|c|}{ All cardiovascular disease } \\
\hline & Relative risk & $95 \% \mathrm{CI}$ & Relative risk & $95 \% \mathrm{CI}$ & Relative risk & $95 \% \mathrm{CI}$ \\
\hline Normoglycaemic & 1.0 & - & 1.0 & - & 1.0 & - \\
\hline Glucose intolerant & 1.2 & $(1.0,1.4)$ & 1.2 & $(1.0,1.5)$ & 1.2 & $(1.0,1.5)$ \\
\hline $\begin{array}{l}\text { Newly diagnosed } \\
\text { diabetic patient }\end{array}$ & 2.0 & $(1.4,2.9)$ & 2.6 & $(1.6,4.2)$ & 2.2 & $(1.4,3.5)$ \\
\hline \multicolumn{7}{|l|}{$\begin{array}{l}\text { Known duration } \\
\text { of diabetes at } \\
\text { examination: }\end{array}$} \\
\hline$\leqslant 2$ years & 2.0 & $(1.1,3.8)$ & 2.3 & $(0.9,6.1)$ & 2.5 & $(1.1,5.6)$ \\
\hline $3-6$ years & 2.0 & $(1.2,3.3)$ & 2.2 & $(1.1,4.7)$ & 2.4 & $(1.3,4.4)$ \\
\hline$\geqslant 7$ years & 1.8 & $(1.0,3.1)$ & 2.5 & $(1.2,5.4)$ & 1.9 & $(0.9,3.9)$ \\
\hline
\end{tabular}

death was made whether or not diabetes mellitus was mentioned on the death certificate. Copies of death certificates were obtained, coding being carried out by the staff of the Registrar General according to the International Classification of Disease (ICD) (8th Revision). The results presented are for men aged 40-64 years at entry.

\section{Statistical analysis}

Mortality rates were calculated using person years at risk and adjustment for age was carried out by direct standardisation, using the total population as standard. The data were also analysed by fitting models as described by Berry [9] using the statistical package GLIM [10]. This allowed age adjusted relative risks and confidence intervals to be calculated from the fitted models. Adjustment for other major risk factors was done using Cox's proportional hazards regression model [11]. These initial analyses divided the diabetic patients into tertiles according to the distribution of duration of diabetes at the Survey examination. However, as follow-up increases so each subject's duration of diabetes increases. Further analyses were per- formed which allow for this time dependence and so are more sensitive to detecting an association with duration of diabetes. Briefly, the person years for each subject were divided into the categories current age at risk and duration of diabetes which allowed adjusted relative risks to be calculated $[9,10]$.

\section{Results}

Table 1 presents the age-adjusted mortality rates and relative risks for all causes of death, CHD - ICD codes (410-414) and CVD - ICD codes (390-458). The calculations of relative risks are in relation to mortality amongst men in centiles 1-95 $(2 \mathrm{~h}$ blood glucose $<5.4 \mathrm{mmol} / \mathrm{l}$ ) of the blood glucose distribution, referred to subsequently as 'normoglycaemic'. The known diabetic men are divided into tertiles of distribution of duration at the Survey examination - 
Table 3. Person years at risk, numbers of deaths, relative risk and $95 \%$ confidence intervals by duration of diabetes in known Type 2 (non-insulin-dependent) and newly diagnosed diabetic groups combined

\begin{tabular}{|c|c|c|c|c|c|c|c|c|c|c|}
\hline \multirow{2}{*}{$\begin{array}{l}\text { Duration of } \\
\text { diabetes }\end{array}$} & \multirow{2}{*}{$\begin{array}{l}\text { Person- } \\
\text { years } \\
\text { at risk }\end{array}$} & \multicolumn{3}{|c|}{ All causes } & \multicolumn{3}{|c|}{ Coronary heart disease } & \multicolumn{3}{|c|}{ All cardiovascular disease } \\
\hline & & $\begin{array}{l}\text { No. } \\
\text { deaths }\end{array}$ & RR & $95 \% \mathrm{CI}$ & $\begin{array}{l}\text { No. } \\
\text { deaths }\end{array}$ & RR & $95 \%$ CI & $\begin{array}{l}\text { No. } \\
\text { deaths }\end{array}$ & RR & $95 \% \mathrm{CI}$ \\
\hline$<5$ years & 408 & 6 & 1.0 & - & 4 & 1.0 & - & 4 & 1.0 & - \\
\hline $5-$ & 571 & 21 & 2.0 & $(0.8,5.0)$ & 12 & 1.8 & $(0.6,5.7)$ & 16 & 2.2 & $(0.7,6.7)$ \\
\hline$\geqslant 20$ & 270 & 5 & 0.9 & $(0.3,3.2)$ & 1 & 0.3 & $(0.0,3.2)$ & 1 & 0.3 & $(0.0,2.8)$ \\
\hline \multicolumn{11}{|c|}{ Chi-square test for; } \\
\hline \multicolumn{2}{|c|}{$\begin{array}{l}\text { Heterogeneity of } \\
\text { relative risks ( } 4 \text { dof) }\end{array}$} & \multicolumn{3}{|c|}{$6.85(p=0.15)$} & \multicolumn{3}{|c|}{$7.38(p=0.12)$} & \multicolumn{3}{|c|}{$11.00(p=0.03)$} \\
\hline
\end{tabular}

Relative risks adjusted for major mortality risk factors; dof - degrees of freedom

$\leqslant 2$ years, $3-6$ years and $\geqslant 7$ years. Because the duration was only known to the nearest whole year, the numbers in each tertile are not equal.

The highest relative risk in each category of mortality occurs in the newly diagnosed diabetic men. There is a significantly increased relative risk $(p<0.05)$ for each category in the glucose intolerant men, as reported previously for the 10-year follow-up [5]. For the known diabetic patients the relative risk estimates show no linear trend across tertiles of increasing duration.

Table 2 presents the relative risk estimates for 15 year mortality from all causes, CHD and CVD derived from a Cox regression analysis incorporating all known risk factors in the Whitehall Study - age, systolic blood pressure, plasma cholesterol, smoking (current, ex- or non-cigarette smoker), work grade and ECG abnormality. This further adjustment diminishes the relative risks for the newly diagnosed diabetic men in each of these categories, becoming similar to that of the previously diagnosed diabetic men. Table 3 presents a more sensitive analysis by looking at current duration of diabetes as described in the methods in the combined group of 177 previously and newly diagnosed Type 2 diabetic men. For this analysis the newly diagnosed men were assumed to have an initial duration of zero. The results show some differences in relative risk with duration of diabetes, though there is again no evidence for a linear trend with increasing duration. The relative risk was lowest in each category of mortality for the longest duration group $(\geqslant 20$ years); because it could be argued that this is a low risk group having survived this long with diabetes we have re-calculated the Chi-squared values for linear trends excluding this group. The results were for all causes $\mathrm{Chi}_{1}^{2}=2.45(p=0.12)$, for $\mathrm{CHD} \mathrm{Chi}_{1}^{2}=1.65$ $(p=0.20)$ and for CVD Chi ${ }_{1}^{2}=2.03(p=0.16)$.

\section{Discussion}

In many, but not all populations, there is a strong association between (ischaemic) coronary heart disease and Type 2 diabetes, evident in both morbidity and mortality statistics $[2,12]$. It has generally been assumed that the relationship is causal, a hypothesis which is apparently supported by the occurrence of abnormalities of lipoproteins, coagulation and haemostatic factors and of blood pressure in Type 2 diabetic patients [12]. However, if the diabetes (i.e. hyperglycaemia and related metabolic disturbances) were the cause, it would be reasonable to expect that cardiovascular risk would increase with diabetes duration in the same way that the incidence of diabetic retinopathy is directly related to duration of disease [3]. A review of the literature [1] did not yield such an association either for mortality ascribed to cardiovascular disease or for degree of coronary atherosclerosis assessed post-mortem.

Assessment of the duration of Type 2 diabetes is, nevertheless, uncertain and many diabetic patients above age 50 years have established retinopathy at the time of clinical diagnosis [13]. In the Whitehall Study it was possible to compare diabetic men found by blood glucose screening with previously diagnosed patients. Even if, in the former group, the duration of diabetes was not zero, it is reasonable to assume that it was less than that of the already diagnosed subjects. Thus, in the Bedford Survey the frequency of retinopathy in diabetic patients diagnosed by a screening process similar to that used in the Whitehall Study was virtually zero at baseline and both frequency and severity were substantially increased five years later [3]. Conversely, in the present analysis of the Whitehall Study, the relative risks for CHD mortality, adjusted for other risk factors, in newly diagnosed and in previously di- 
agnosed diabetic men did not show a linear trend across the range of known duration, in confirmation of the results of the 10-year follow-up where no effect of duration upon mortality risk could be seen in the previously diagnosed diabetic men [4]. The glucose intolerant men had mortality rates intermediate between the normoglycaemic and diabetic men. In accordance with the hypothesis, the increased risk in the glucose intolerant men could be interpreted as due to a higher proportion of pre-diabetic subjects amongst them [14].

The concept that Type 2 diabetes and cardiovascular disease are associated conditions, not causally related, and that diabetes occurs more frequently in individuals predisposed to develop cardiovascular disease has received support from the observation in the Framingham Study [15] that in those aged 50 years or more the subsequent incidence of diabetes was increased in those with pre-existing vascular disease. A genetically determined link between Type 2 diabetes and CVD is currently hypothetical but receives some support from the finding of an increased prevalence of an uncommon allelic variant of the apoprotein AI CIII - AIV gene cluster in Type 2 diabetic patients with coronary heart disease [16].

\section{References}

1. Jarrett RJ (1984) Type 2 (non-insulin-dependent) diabetes mellitus and coronary heart disease - chicken, egg or neither? Diabetologia 26: 99-102

2. Panzram G (1987) Mortality and survival in Type 2 (non-insulindependent) diabetes mellitus. Diabetologia 30:123-131

3. Jarrett RJ (1983) Microvascular disease in diabetes mellitus. In: Mann JI, Pyörälä K, Teuscher A (eds) Diabetes in Epidemiological Perspective. Churchill Livingstone, Edinburgh, pp 248-264

4. Jarrett RJ, Shipley MJ (1985) Mortality and associated risk factors in diabetes. Acta Endocrinol [Suppl] 272: 21-26
5. Fuller JH, Shipley MJ, Rose G, Jarrett RJ, Keen H (1983) Mortality from coronary heart disease and stroke in relation to degree of glycaemia; the Whitehall Study. Br Med J 287: 867-870

6. Reid DD, Brett GZ, Hamilton PJS, Jarrett RJ, Keen H, Rose GA (1974) Cardiorespiratory disease and diabetes among middleaged male Civil Servants: a study of screening and intervention. Lancet I: 469-473

7. Diabetes Mellitus: report of a WHO Study Group (1985) Tech Rep Ser No 727. World Health Organisation, Geneva

8. Rose G, Blackburn H (1968) Cardiovascular survey methods. WHO Monograph Series No 56. WHO, Geneva

9. Berry $G$ (1983) The analysis of mortality by the subject-years method. Biometrics 39: 178-184

10. Baker RJ, Nelder JA (1978) The GLIM system release 3; generalised linear-interactive modelling. Numerical Algorithms Group, Oxford

11. Cox DR (1972) Regression models and life tables. J R Statist Soc B 34: $187-220$

12. Jarrett RJ, Keen H, Chakrabarti R (1982) Diabetes, hyperglycaemia and arterial disease. In: Keen H, Jarrett $\mathrm{J}$ (eds) Complications of Diabetes, 2nd edn. Edward Arnold, London, pp 179-203

13. Soler NG, Fitzgerald MG, Malins JM, Summer ROC (1969) Retinopathy at diagnosis of diabetes, with special reference to patients under 40 years of age. Br Med J 3: 567-569

14. Jarrett RJ, Keen H, McCartney P (1984) The Whitehall Study: ten year follow-up report on men with impaired glucose tolerance with reference to worsening to diabetes and predictors of death. Diabetic Medicine 1: 279-283

15. Wilson PWF, Anderson KM, Kannel WB (1986) Epidemiology of diabetes mellitus in the elderly. Am J Med 80 [Suppl5A]: 3-9

16. Trembath RC, Thomas DJB, Hendra TJ, Yudkin JS, Galton DJ (1987) Deoxyribonucleic acid polymorphism of the apoprotein AI - CIII - AIV gene cluster and coronary heart disease in noninsulin-dependent diabetes. Br Med J 294: 1577-1578

Received: 6 April 1988

and in revised form: 23 August 1988

Prof. R.J.Jarrett

Division of Community Health

U.M.D.S. (Guy's Campus)

London, SE1 9RT

UK 